\title{
Motor Stator Winding Condition Monitoring
}

This paper was downloaded from TechRxiv (https://www.techrxiv.org).

\section{LICENSE}

CC BY 4.0

SUBMISSION DATE / POSTED DATE

$13-10-2021 / 18-10-2021$

CITATION

Joey, Ang (2021): Motor Stator Winding Condition Monitoring. TechRxiv. Preprint. https://doi.org/10.36227/techrxiv.16800007.v1

$\mathrm{DOI}$

10.36227/techrxiv.16800007.v1 


\title{
Motor Stator Winding Condition Monitoring
}

\author{
Ang Joey
}

\begin{abstract}
The induction motor is considered the workhorse of the industry as it is used in most of the engineering applications. It is essential to ensure a safe and reliable operation of the induction motor in every system. Among the various types of induction motor faults, stator winding insulation fault accounts for a high percentage of it. As such, being able to detect early stages of insulation faults within the equipment using the method proposed in this paper would prove to be useful in providing timely maintenance. The proposed method in this paper is the non-intrusive impedance extraction method for online stator winding fault detection of induction motor. By observing the health condition of the motor in relation with its impedance, early stages of faults can be detected and rectified. Hence, eliminating potential safety hazards, reducing motor downtime as well as lowering the cost of maintenance. Experimental results shown will prove the reliability and accuracy in which the method proposed would provide. At the same time, its installation and removal are less complicated as compared to other methods hence is cost and time efficient.
\end{abstract}

Keywords: Induction motor, impedance extraction, stator winding, fault detection

\section{Introduction}

In almost all engineering applications, the induction motors (IM) are considered the workhorse within the industry [1]. It comprises of two key components; rotor, the rotating part of the motor as well as the stationary part called the stator. By electromagnetic induction, the power is transferred from one part to another. Apart from the two main components mentioned above, an induction motor consists of other parts such as the bearings which is usually located at either end of the motor. The bearings reduce the friction between the moving parts hence increasing the efficiency of the induction motor.

Due to its rugged construction, simplicity, high efficiency and relatively low manufacturing costs, the induction motor is commonly used as a mean to power industrial equipment. They are mainly used in environment which require high operation time however are subjected to undesirable faults. As such, its health condition is essential to ensure an unwavering and dependable operation of modern industrial systems. There are various types of induction motor faults, which are common in the industry such as damaged rotor bars, dynamic or static air gap irregularities, stator windings insulation faults and bent shaft etc. However, past statistics have shown that stator winding breakdown has contributed to a large percentage of induction motor failures [2], [3].

For this paper, a non-intrusive impedance extraction online method that is based on the inductive coupling approach [4-7], is used for detecting insulation fault within the stator winding of the induction motor. A known signal generated is input into the induction motor and monitored simultaneously. The impedance obtained through the signal will be extracted. By observing the health condition and its impedance, early stages of fault can be detected and rectified. This method eliminates potential safety hazards and its installation and removal is less complicated as compared to other methods hence is cost and time efficient.

\section{Methodology}

Figure 1 shows the fundamental measurement setup of the circuit loop with an oscilloscope, signal generator and two clamp-on probes, namely the current injecting probe and current receiving probe. The Device Under Test (DUT), power supply as denoted by $\mathrm{V}_{\mathrm{S}}$ in the figure below, as well as the connecting wires established a closed-circuit loop. $Z_{\text {DUT }}, Z_{\text {Wire }}$ and $Z_{\text {Supply }}$, denotes the impedances of the DUT, power supply and connecting wires respectively. 


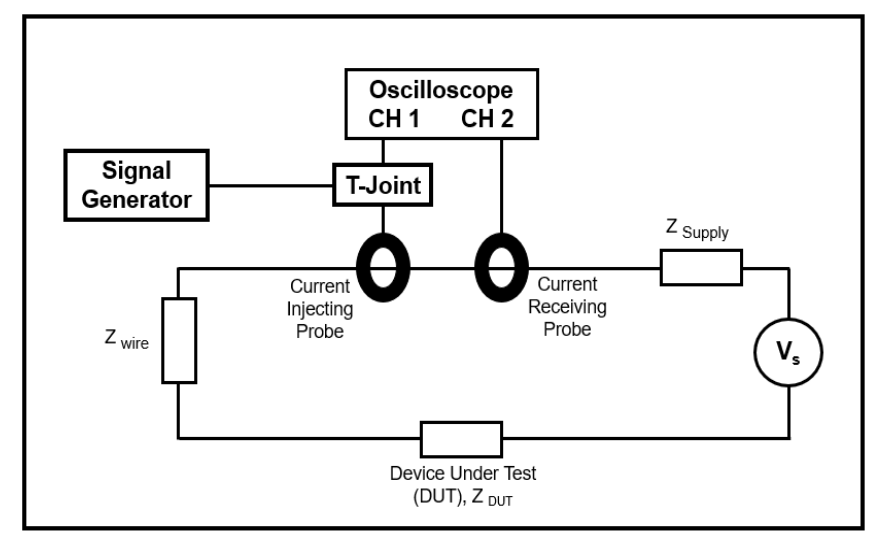

Figure 1 - Fundamental Measurement Setup of the Circuit Loop.

Hence, the closed-circuit loop impedance, $Z_{\text {Loop }}$ is obtained through the equation:

$$
Z_{\text {Loop }}=Z_{\text {DUT }}+Z_{\text {Wire }}+Z_{\text {Supply }}
$$

The signal generator simulates a known sinusoidal signal which is injected into the circuit loop through the oscilloscope $\mathrm{CH} 1$. At the same time, the receiving probe will monitor and measure the same signal through the oscilloscope $\mathrm{CH} 2$. A cascaded two-port network approach will be applied to draw out the unknown impedance of the DUT [8]. The resultant, $\mathrm{M}$ of the cascaded two-port network is given by:

$$
\mathrm{M}=\mathrm{M}_{\text {inject }} \times \mathrm{M}_{\text {loop }} \times \mathrm{M}_{\text {receive }}
$$

The general two-port network observed by the Oscilloscope is given by:

$$
\left[\begin{array}{c}
V 1 \\
I 1
\end{array}\right]=\left[\begin{array}{cc}
A_{\text {inj }} & B_{i n j} \\
C_{\text {inj }} & D_{\text {inj }}
\end{array}\right]\left[\begin{array}{cc}
1 & Z_{\text {loop }} \\
0 & 1
\end{array}\right]\left[\begin{array}{ll}
A_{\text {rec }} & B_{\text {rec }} \\
C_{\text {rec }} & D_{\text {rec }}
\end{array}\right]\left[\begin{array}{c}
V 2 \\
I 2
\end{array}\right]
$$

Given that $\mathrm{I}_{2}=\frac{V 2}{50}, \mathrm{Z}_{\text {loop }}$ can be extracted as follows:

$$
Z_{\text {loop }}=\frac{V 1}{V 2} \times \frac{1}{A_{i n j} \times\left(C_{r e c}+\frac{D_{r e c}}{50}\right)}-\frac{A_{r e c}+\frac{B_{r e c}}{50}}{C_{r e c}+\frac{D_{r e c}}{50}}-\frac{B_{i n j}}{A_{i n j}}
$$

Utilising a test fixture as shown in Figure 2, $\mathrm{M}_{\text {inject }}$ and $\mathrm{M}_{\text {receive }}$ can be pre-characterized. The inductive probe is fastened onto the wire of the test fixture. The ends of the wire are connected to the outer conductor and the signal terminal of the test fixture respectively. At the same time, the ground terminal of the port is connected to the outer conductor. For $\mathrm{M}_{\text {inject }}$ to be characterized, the injecting probe port will be connected to Port 1 of the VNA and Port 2 will be connected to the test fixture port. In the case of characterization of $\mathrm{M}_{\text {receive, }}$, the test fixture port will now be connected to Port 1 of the VNA and Port 2 will be connected to the receiving probe port.

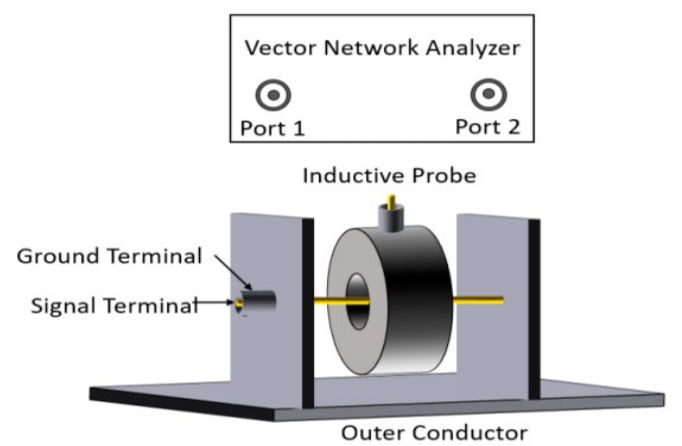

Figure 2 - Test Fixture with Vector Network Analyzer and Inductive Probe [13] 
Hence, with this setup, the VNA can measure the respective two-port parameters of the probes with the wire directly. The extracted data will be change into the ABCD parameters based on the equations shown below [9]. Given that $\mathrm{Z}_{0}=50 \Omega$.

$$
\begin{aligned}
& A=\frac{\left(1+S_{11}\right)\left(1-S_{22}\right)+\left(S_{12} S_{21}\right)}{2 S_{21}} \\
& B=Z_{0} \frac{\left(1+S_{11}\right)\left(1+S_{22}\right)-\left(S_{12} S_{21}\right)}{2 S_{21}} \\
& C=\frac{1}{Z_{0}} \frac{\left(1-S_{11}\right)\left(1-S_{22}\right)-\left(S_{12} S_{21}\right)}{2 S_{21}} \\
& D=\frac{\left(1-S_{11}\right)\left(1+S_{22}\right)+\left(S_{12} S_{21}\right)}{2 S_{21}}
\end{aligned}
$$

After pre-characterizing $\mathrm{M}_{\text {inject }}$ and $\mathrm{M}_{\text {receive, }} \mathrm{Z}_{\text {loop }}$ can be extracted when $\mathrm{V}_{1}$ and $\mathrm{V}_{2}$ are obtained. A moving window Discrete Fourier Transform (DFT) algorithm is used to obtain the magnitudes and phases of $\mathrm{V}_{1}$ and $\mathrm{V}_{2}$. With the window size $\mathrm{N}$ set at a constant value, DFT is performed to obtain the dynamic voltage equivalents at different time instances, hence obtaining $\mathrm{V}_{1}$ and $\mathrm{V}_{2}$.

As shown in Figure 3, when time is equals to zero, the program begins with the samples of $v_{1}(t)$ and $\mathrm{v}_{2}(\mathrm{t})$. At the same time, ' $\mathrm{m}$ ' corresponds to the $(\mathrm{m}+1)^{\mathrm{th}}$ sample during the entire monitoring procedure, which is the same as multiplication of the sampling time point $t$ and the sampling rate $\frac{1}{\Delta t}$. When $(\mathrm{m} \geq$ $\mathrm{N}-1$ ), the DFT is excecuted and $\mathrm{V}_{1}$ and $\mathrm{V}_{2}$ are obtained. Acquiring of $\mathrm{V}_{1}$ and $\mathrm{V}_{2}$ at time $\mathrm{t}$ is based on the latest samples within the time domain, which is from $(\mathrm{m}-\mathrm{N}+1) \Delta t$ to $\mathrm{m} \Delta t$. Therefore, the $\mathrm{N}$ samples are determined and are relative to the sampling time instance t. Once achieving $V_{2}$ at time instance $t$, the corresponding $\mathrm{I}_{2}$ can also be extracted. Thus, $\mathrm{Z}_{\mathrm{SUM}}$ at that time point $\mathrm{t}$ can be calculated and subsequently $Z_{\mathrm{TVN}}$ is determined. Lastly, the algorithm will compare whether the sampling time point $t$ has reached the last sampling time point $\left(t_{\text {end }}\right)$. The algorithm will end when $t \geq t_{\text {end }}$ otherwise the same process is repeated till the condition is fulfilled.

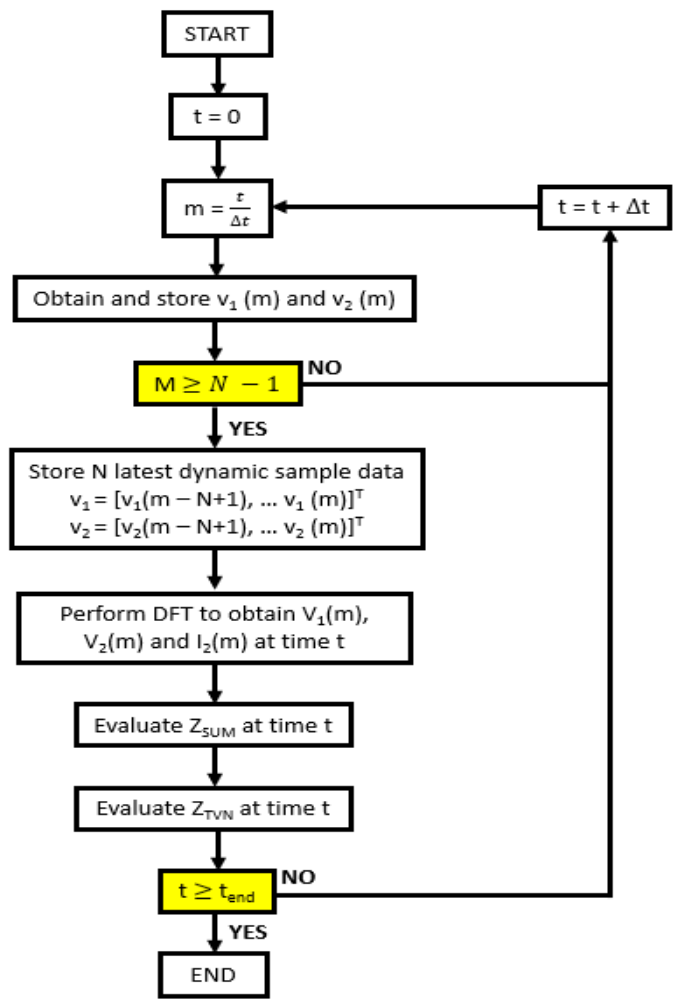

Figure 3 - Moving Window Discrete Fourier Transform Algorithm 
Hence the DFT can be used to monitor $Z_{\text {loop }}$ in real time [7]. Once V1 and V2 are obtained, $Z_{\text {loop }}$ can be obtained through the equation stated above. By de-embedding the components $Z_{\text {Wire }}$ and $Z_{\text {Supply }}$ from $Z_{\text {loop, }} Z_{\text {DUT }}$ can be extracted. In the case where $Z_{\text {Wire }}$ and $Z_{\text {Supply }}$ values are small and negligible, they can be ignored.

\section{Experiment Validation}

\section{A. Verification of Accuracy of Proposed Setup}

To verify the precision of the suggested measurement setup, several components such as resistors, capacitors and inductors with known values are used to represent different DUTs. In this validation experiment, the following parameters are set at a fixed value:

$$
\begin{gathered}
\mathrm{F}_{\text {Signal }}=100 \mathrm{kHz} \\
\mathrm{F}_{\text {Sampling }}=1 \mathrm{MHz} \\
\mathrm{N}=100
\end{gathered}
$$

For the suggested method, selecting a suitable $\mathrm{F}_{\text {Signal }}$ is essential. To extract the impedance accurately, the intervals between the period of $\mathrm{N}$ samples should be smaller than that of the impedance change. Hence,

$$
\begin{gathered}
F_{\text {Sampling }}=\mathrm{N}_{\mathrm{p}} \cdot \mathrm{F}_{\text {Signal }} \\
\mathrm{N}=\mathrm{N}_{\mathrm{p}} \cdot \mathrm{N}_{\mathrm{c}}
\end{gathered}
$$

where $\mathrm{N}_{\mathrm{p}}$ is the number of samples for each cycle of $\mathrm{F}_{\text {Signal }}, \mathrm{N}_{\mathrm{c}}$ is the number of cycles of $\mathrm{F}_{\text {Signal }}$ to carry out the DFT. In this paper, both $\mathrm{N}_{\mathrm{p}}$ and $\mathrm{N}_{\mathrm{c}}$ will be set at a constant value of 10 for all experiment. Thus, utilizing the proposed method, the circuit loop is injected with the test signal, $F_{\text {Signal }}$ and the real time impedances of the various DUTs are computed. The following figures below shows some of the measured impedances of the various DUTs (Resistors, Capacitors \& Inductors) using the suggested method. The solid line represents the measured value and the dashed line represent the calculated value. For a resistor with resistance of $1 \mathrm{k} \Omega$. From Figure 4, for a resistor with impedance of $1000 \Omega$, the measured magnitude values can be observed to be at approximately $1000 \Omega$. Real time data statistics of the resistor show that measured impedance is given at $1008 \Omega$ as shown in Figure 5. And the phase of the same resistor is given at approximately $0^{\circ}$ as seen in Figure 5 and Figure 6 below. The measured value can be considered accurate as it is within $5 \%$ tolerance level of the calculated value. This discrepancy is due to the manufacturing of the individual components.

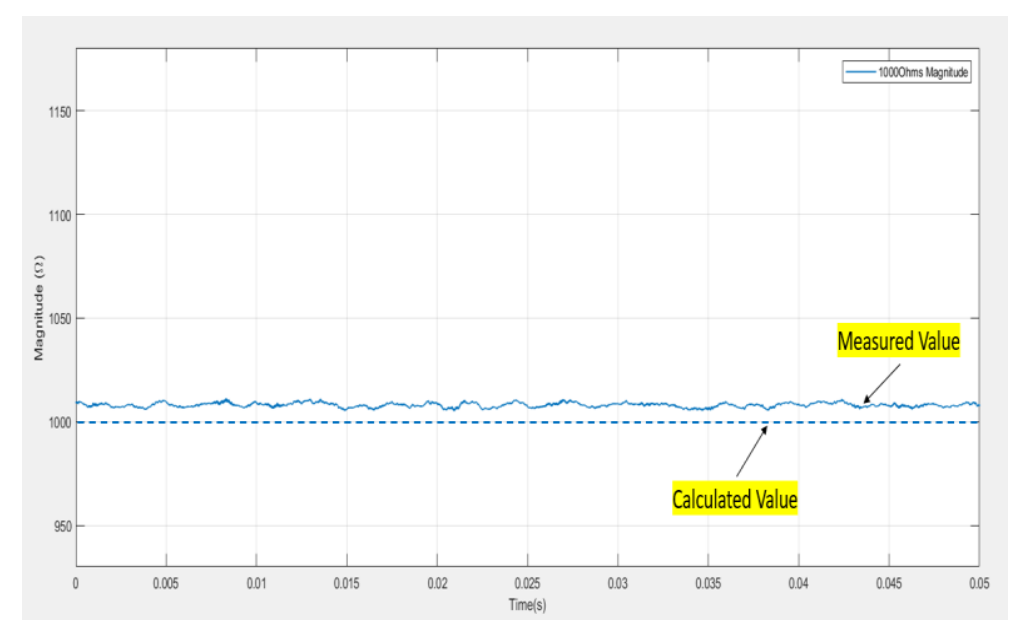

Figure 4 - Measured Magnitude of $1000 \Omega$ Resistor at given parameters 


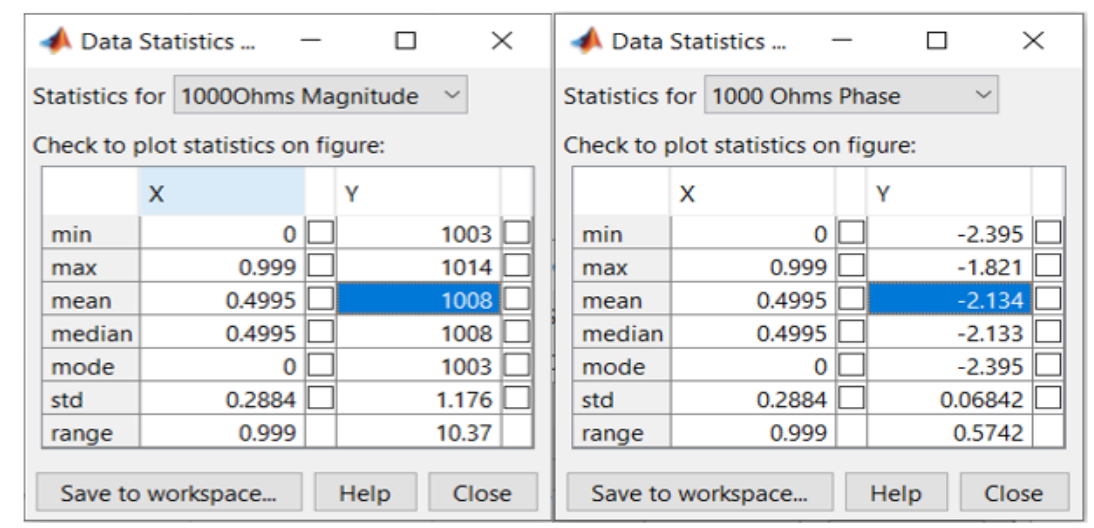

Figure 5 - Data Statistics of 1000 Ohms Resistor

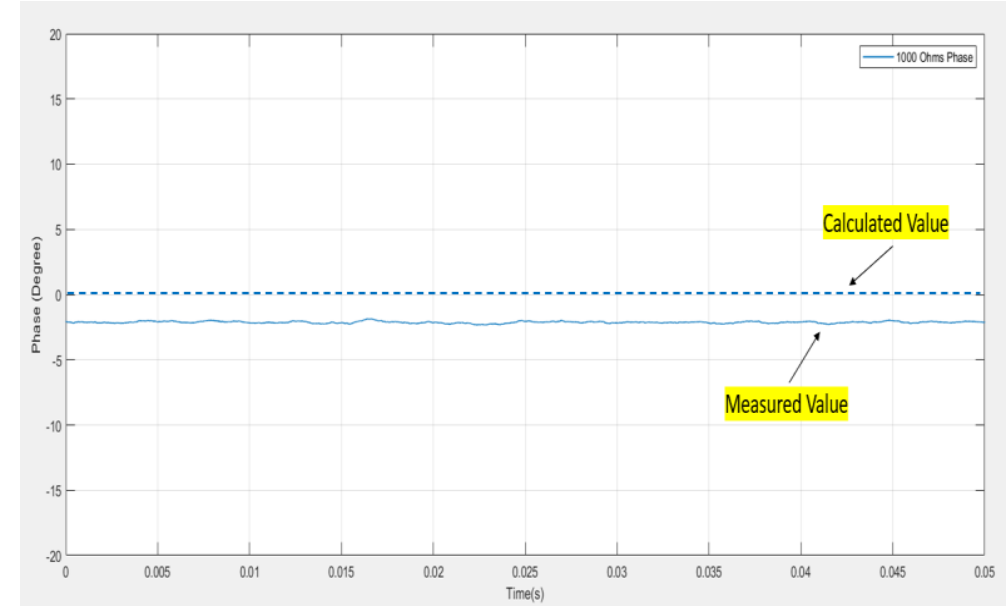

Figure 6-Measured Phase of $1000 \Omega$ Resistor at given parameters

In the case of a capacitor, the impedance can be obtained through the formula:

$$
Z=\frac{1}{2 \pi f c}
$$

For a capacitor with capacitance of $82 \mathrm{nF}$, the corresponding impedance is given by:

$$
Z=\frac{1}{2 \times \pi \times\left(100 \times 10^{3}\right) \times\left(82 \times 10^{-9}\right)} \approx 19.5 \Omega
$$

Phase of a capacitor is given at $-90^{\circ}$.

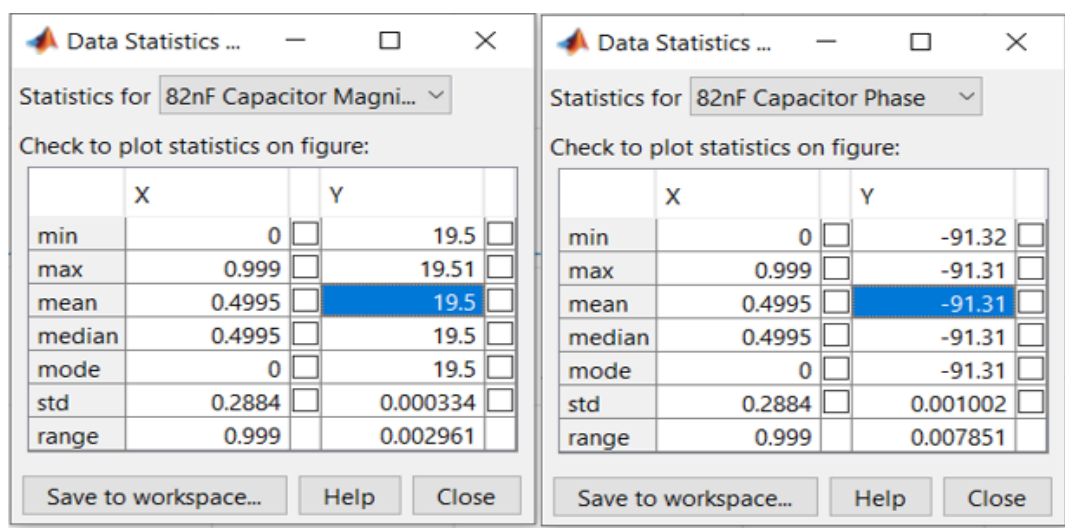

Figure 7 - Data Statistics of 82nF Capacitor 
The data statistics of the $82 \mathrm{nF}$ Capacitor state that the measured impedance magnitude is at $19.5 \Omega$ and phase is at $-91.31^{\circ}$ as shown in Figure 7 . These results can also be observed in the magnitude and phase waveform obtained as shown in Figure 8 and Figure 9, respectively. The measured value is almost the same as the calculated value.

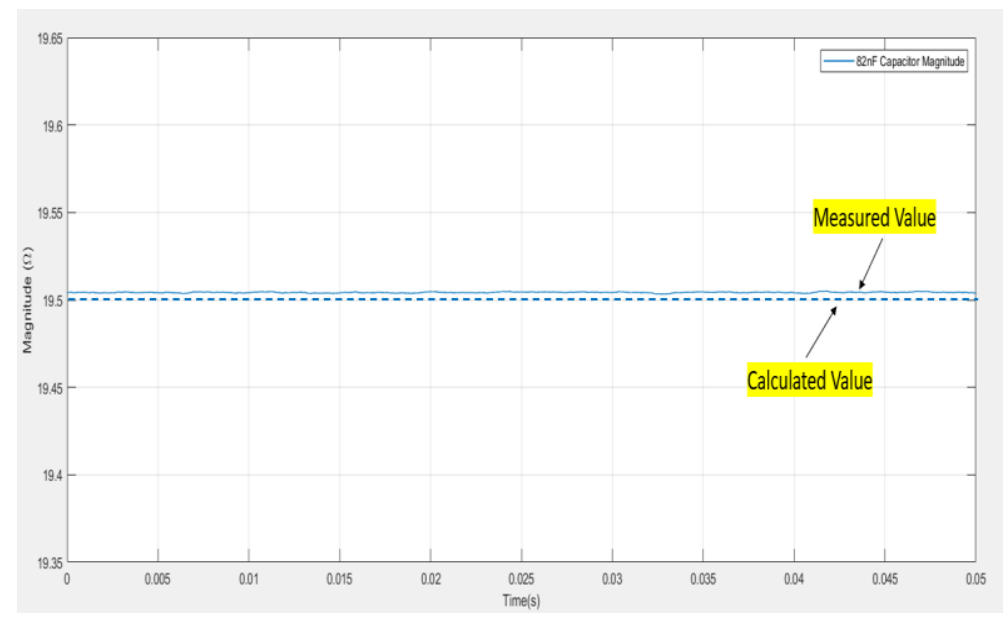

Figure 8 - Measured Magnitude of 82nF Capacitor at given parameters

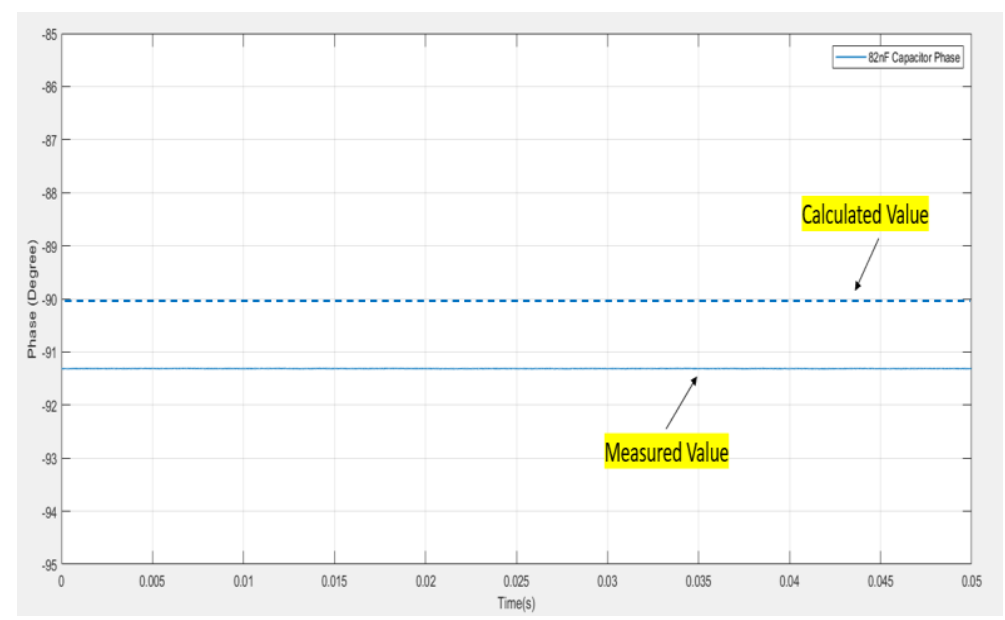

Figure 9 - Measured Phase of $82 n F$ Capacitor at given parameters

In the case of an inductor, the impedance can be obtained through the formula:

$$
Z=2 \pi f L
$$

For an inductor of inductance $\underline{82 \mu \mathrm{H}}$, the corresponding impedance is given by:

$$
Z=2 \times \pi \times\left(100 \times 10^{3}\right) \times\left(82 \times 10^{-6}\right) \approx 51.5 \Omega
$$

Phase of an inductor is given at $90^{\circ}$. 


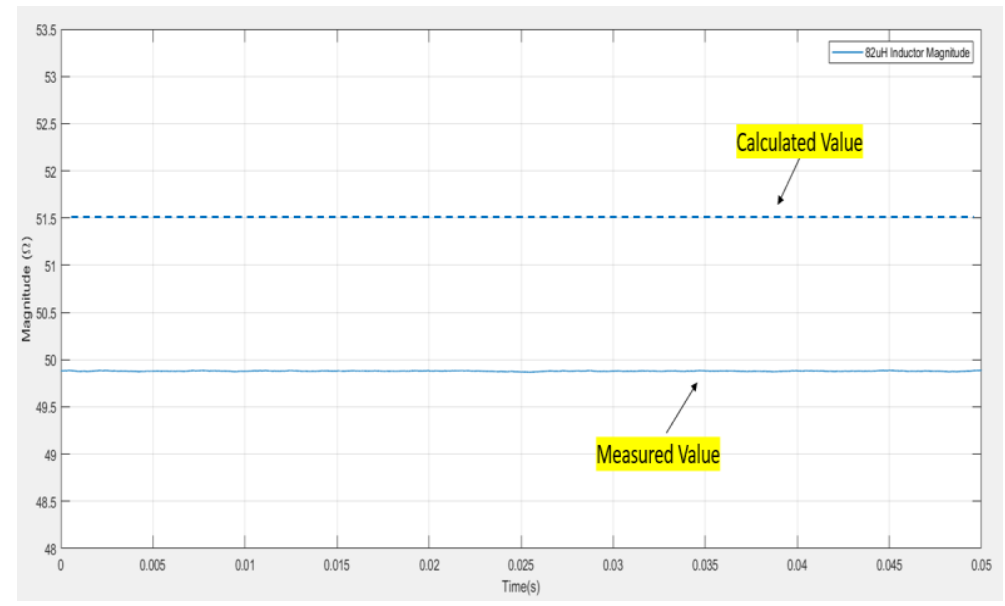

Figure 10 - Measured Magnitude of $82 u H$ Inductor at given parameters

\begin{tabular}{|c|c|c|c|c|c|c|c|c|c|c|c|c|}
\hline \multicolumn{2}{|c|}{ A Data Statistics ... } & - & & $\square$ & \multirow[t]{2}{*}{$\times$} & \multicolumn{2}{|c|}{ A Data Statistics ... } & - & \multicolumn{2}{|c|}{$\square$} & \multicolumn{2}{|c|}{$\times$} \\
\hline \multicolumn{5}{|c|}{$\begin{array}{l}\text { Statistics for } 82 \mathrm{uH} \text { Inductor Magnit... } \\
\text { Check to plot statistics on figure: }\end{array}$} & & \multicolumn{7}{|c|}{$\begin{array}{l}\text { Statistics for } 82 \mathrm{uH} \text { Inductor Phase } \\
\text { Check to plot statistics on figure: }\end{array}$} \\
\hline & $x$ & & Y & & & & $x$ & & Y & & & \\
\hline $\min$ & 0 & 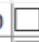 & & 49.86 & & $\min$ & 0 & $\square$ & & 84.5 & & \\
\hline $\max$ & 0.999 & $\square$ & & 49.89 & & $\max$ & 0.999 & 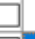 & & 84.5 & & 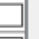 \\
\hline mean & 0.4995 & $\square$ & & 49.88 & & mean & 0.4995 & 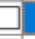 & & 84.5 & & \\
\hline median & 0.4995 & 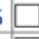 & & 49.88 & & median & 0.4995 & $\sqsupseteq$ & & 84.5 & & $\square$ \\
\hline mode & 0 & 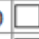 & & 49.86 & & mode & 0 & $\sqsupseteq$ & & 84.5 & & \\
\hline std & 0.2884 & $t$ & & 0.003408 & & std & 0.2884 & & & 0.00382 & & \\
\hline range & 0.999 & & & 0.03032 & & range & 0.999 & & & 0.0364 & & \\
\hline \multicolumn{2}{|c|}{ Save to workspace... } & & Help & Clos & & \multicolumn{2}{|c|}{ Save to workspace... } & & Help & & ose & \\
\hline
\end{tabular}

Figure 11 - Data Statistics of $82 u H$ Inductor

For an inductor with inductance of $82 \mu \mathrm{H}$, its impedance calculated from the formula is $51.5 \Omega$ and its phase is $90^{\circ}$. Based on the Figure 10 and Figure 11 above, it is observed that the measured value is within the $5 \%$ tolerance level. The phase value can also be seen to be close to the theoretical value as seen in Figure 12.

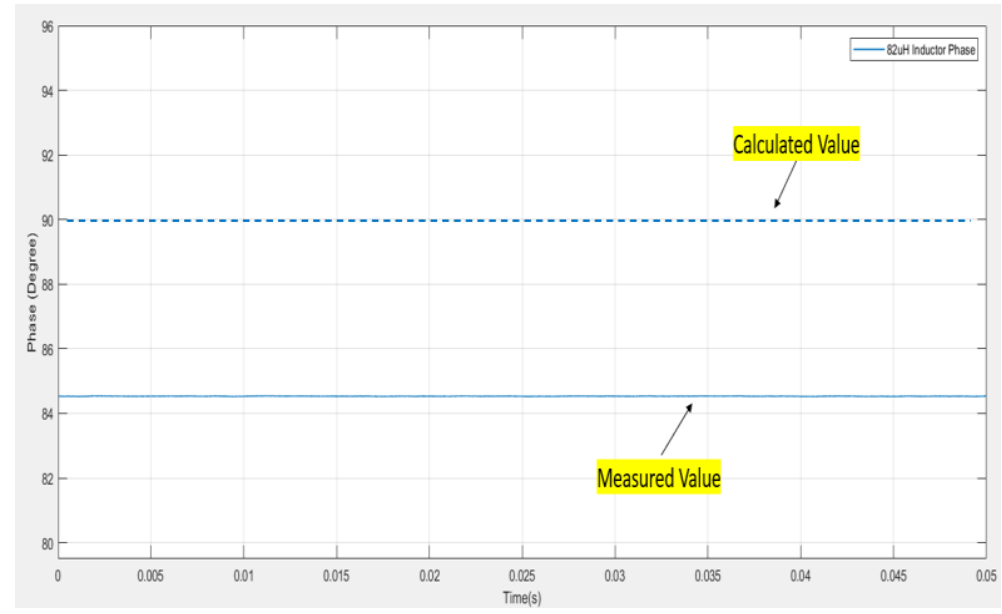

Figure 12 - Measured Phase of $82 u H$ Inductor at given parameters 
As seen from the figures above, the determined impedances utilizing the suggested method display close agreement with the values calculated through theoretical formulas. This prove that the suggested method can extract the impedance of the DUT with good precision.

\section{B. Healthy State of an Induction Motor}

For the monitoring of the online condition of a single-phase induction motor, the same oscilloscope and current probes as seen in the earlier experiment will be used. Figure 13 below shows the basic configuration for the online monitoring.

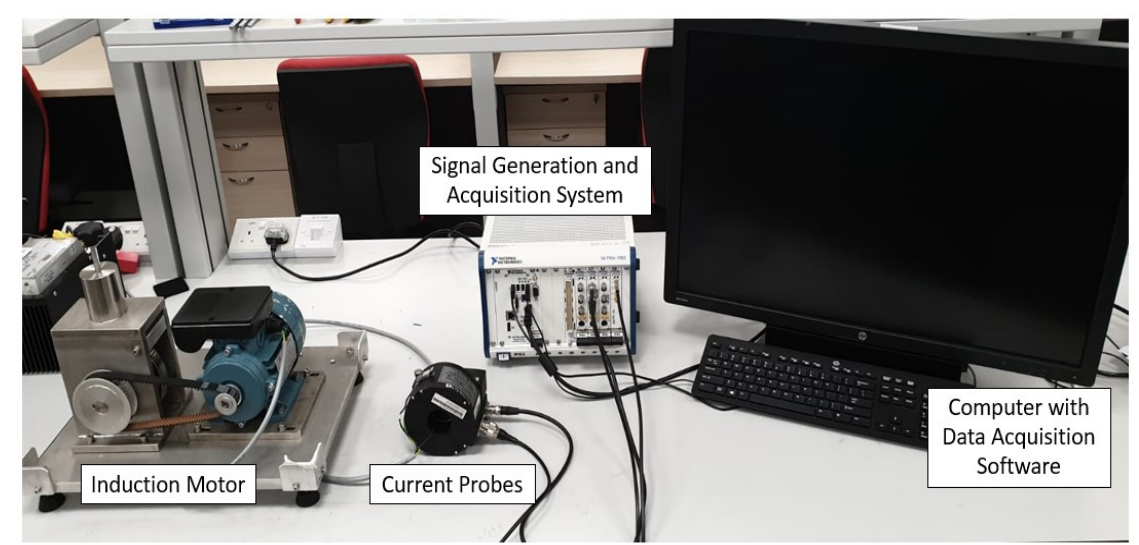

Figure 13 - Setup for Monitoring of Single-Phase Induction Motor

For online $\mathrm{CM}$ of the induction motor, the healthy state condition is essential. Hence, the first step of the suggested method is to retrieve the impedance of the IM in its healthy condition with no faults. For this part of the experiment, we will extract the healthy state impedance of the induction motor with light load and heavy load at 3 different frequencies, $100 \mathrm{kHz}, 200 \mathrm{kHz}$ and $400 \mathrm{kHz}$ respectively. Under the following conditions, the impedance of the IM in its healthy state is extracted.

When light load is attached to the induction motor,

$$
\begin{gathered}
\mathrm{F}_{\text {Signal }}=100 \mathrm{kHz}, 200 \mathrm{kHz}, 400 \mathrm{kHz} \text { respectively } \\
\mathrm{N}=100
\end{gathered}
$$

Figures 14-16 show the measured magnitude of the impedance of the induction motor with light load in their healthy state at the stated frequencies.

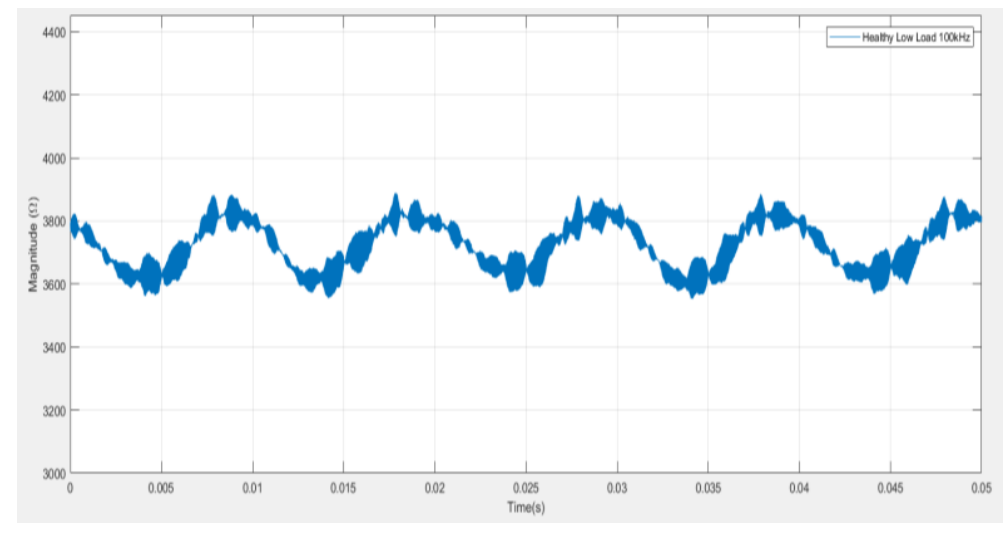

Figure 14 - Light Load Healthy State Magnitude, Fsig is 100kHz, Fs is $1 \mathrm{MHz}$ 


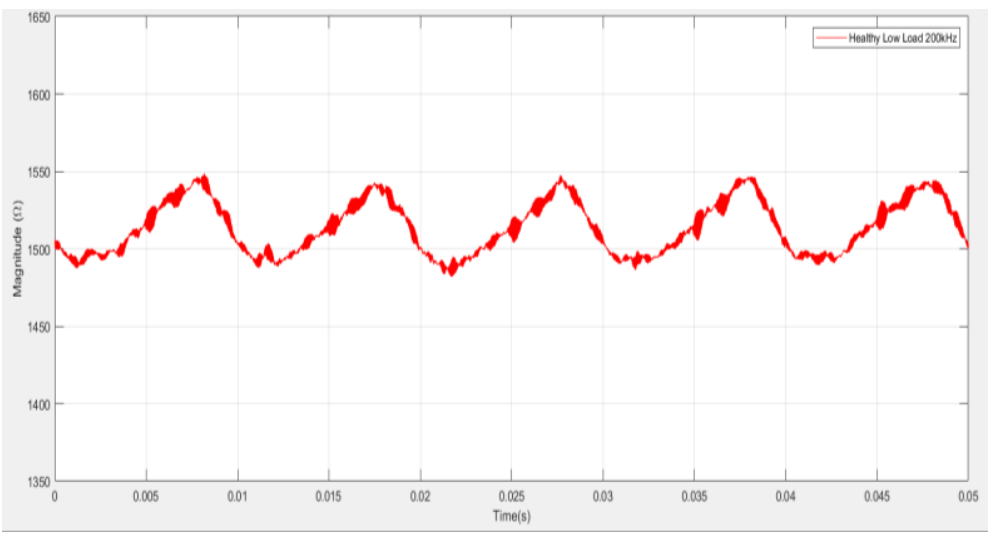

Figure 15 - Light Load Healthy State Magnitude, Fsig is 200kHz, Fs is $2 \mathrm{MHz}$

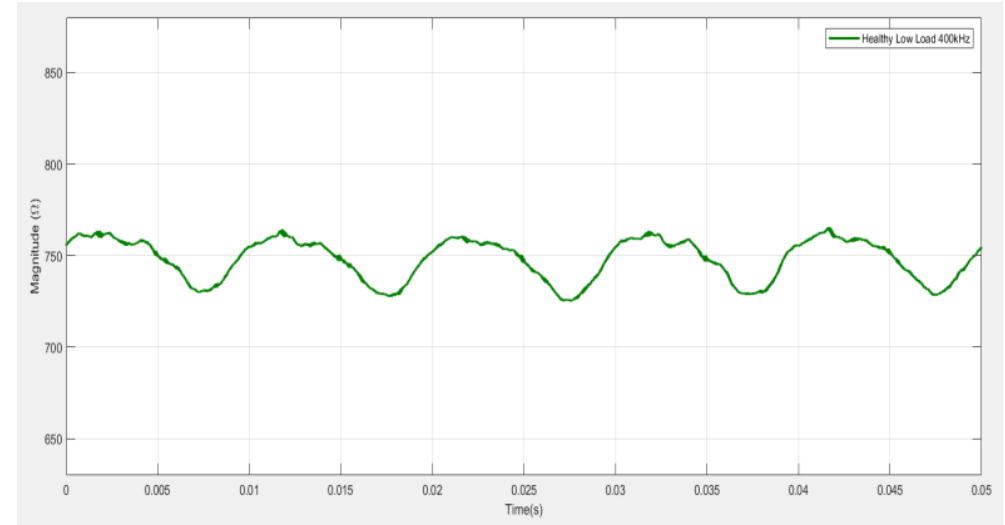

Figure 16 - Light Load Healthy State Magnitude, Fsig400kHz, Fs $4 \mathrm{MHz}$

When heavy load is attached to the induction motor,

$$
\mathrm{F}_{\text {Signal }}=100 \mathrm{kHz}, 200 \mathrm{kHz}, 400 \mathrm{kHz} \text { respectively }
$$

$$
\mathrm{N}=100
$$

Figures 17-19 show the measured magnitude of the impedance of the induction motor with heavy load in their healthy state at the stated frequencies.

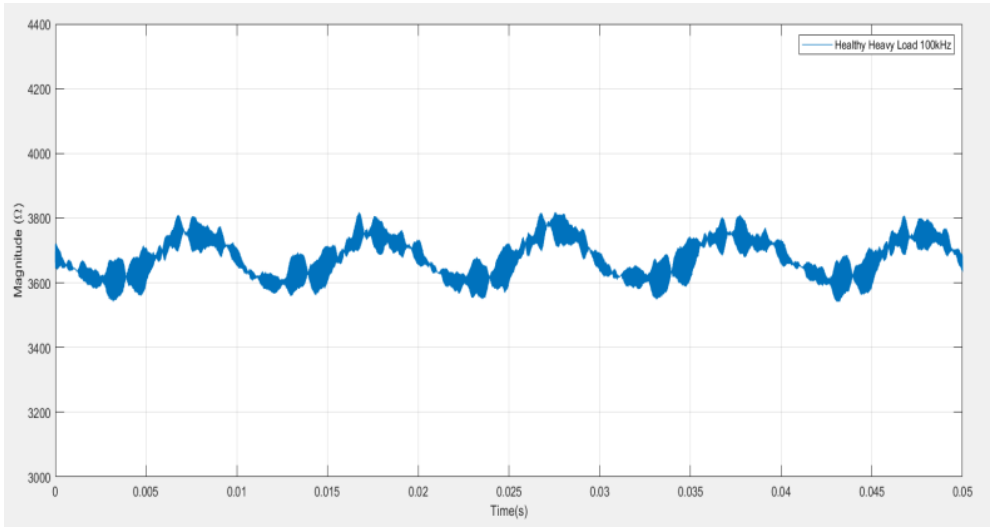

Figure 17 - Heavy Load Healthy State Magnitude, Fsig is 100kHz, Fs is $1 \mathrm{MHz}$ 


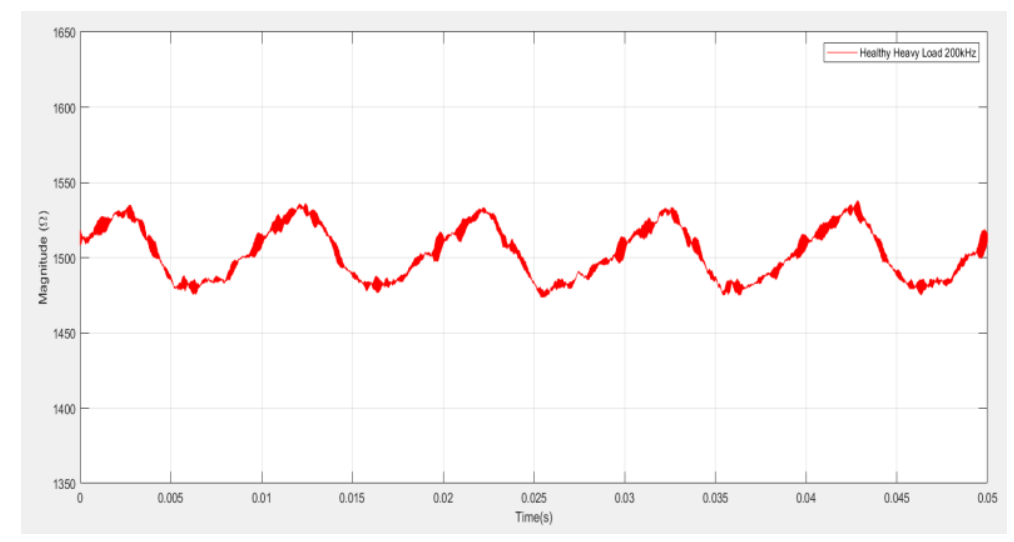

Figure 18 - Heavy Load Healthy State Magnitude, Fsig is 200kHz, Fs is $2 \mathrm{MHz}$

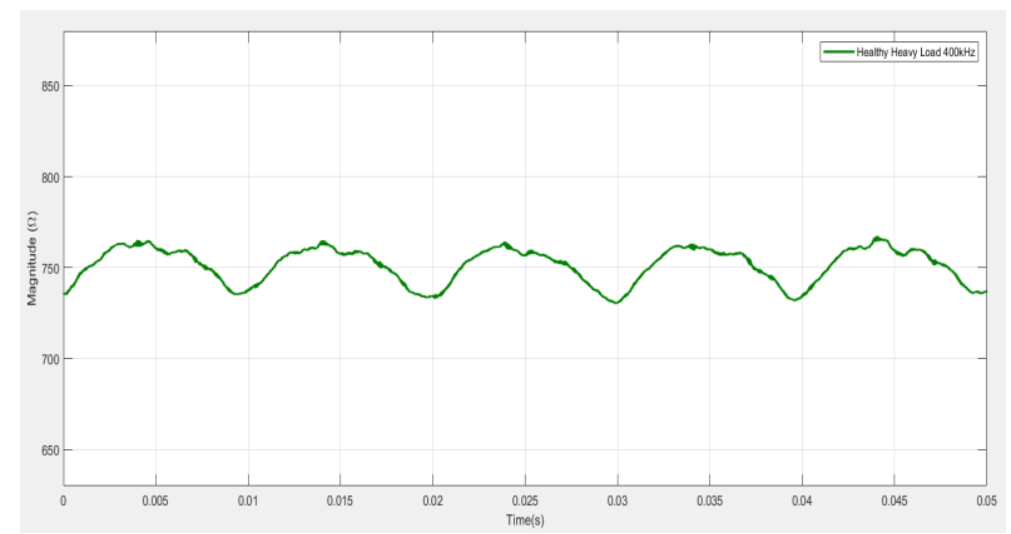

Figure 19 - Heavy Load Healthy State Magnitude, Fsig is 400kHz, Fs is $4 \mathrm{MHz}$

Despite a heavy load attached to the induction motor, the impedance extracted is of close agreement with that of the induction motor with a light load attached at the same frequency level. This is proven from the waveform above as well as the data statistics table shown in Figure 20 and Figure 21. Based on the real time data extracted, it is shown that the impedances for both low load and heavy load does not differ much in comparison.

\begin{tabular}{|c|c|c|c|c|c|c|c|c|c|c|c|c|}
\hline \multicolumn{2}{|c|}{ A Data Statistics ... } & [ & X & \multicolumn{2}{|c|}{ A Data Statistics ... } & & $X$ & \multicolumn{2}{|c|}{ A Data Statistics ... } & & & $x$ \\
\hline \multicolumn{4}{|c|}{$\begin{array}{l}\text { Statistics for } 100 \mathrm{kHz} \text { _LowLoad Ma... } \\
\text { Check to plot statistics on figure: }\end{array}$} & \multicolumn{4}{|c|}{$\begin{array}{l}\text { Statistics for } 200 \mathrm{kHz} \_ \text {LowLoad Ma... } \\
\text { Check to plot statistics on figure: }\end{array}$} & \multicolumn{5}{|c|}{$\begin{array}{l}\text { Statistics for } 400 \mathrm{kHz} \text { _LowLoad_Ma... } v \\
\text { Check to plot statistics on figure: }\end{array}$} \\
\hline & $x$ & Y & & & $x$ & $\mathrm{Y}$ & & & $x$ & Y & & \\
\hline $\min$ & 0 & & 3534 [ & $\min$ & 0 & & 1482 & $\min$ & 0 & & 725 & \\
\hline $\max$ & 0.999 & & 3922 & $\max$ & 0.4995 & & 1550 & $\max$ & 0.2497 & & 766.5 & \\
\hline mean & 0.4995 & & 3724[ & mean & 0.2497 & & 1513[ & mean & 0.1249 & & 747.9 & \\
\hline median & 0.4995 & & 3727[ & median & 0.2497 & & 1511 & median & 0.1249 & & 751.6 & \\
\hline mode & 0 & & 3534 & mode & 0 & & 1482 & mode & 0 & & 725 & \\
\hline std & 0.2884 & & 75.03 & std & 0.1442 & & 17.09 & std & 0.0721 & & 11.23 & \\
\hline range & 0.999 & & 387.8 & range & 0.4995 & & 67.8 & range & 0.2497 & & 41.48 & \\
\hline \multicolumn{2}{|c|}{ Save to workspace... } & Help & Close & \multicolumn{2}{|c|}{ Save to workspace... } & Help & Close & \multicolumn{2}{|c|}{ Save to workspace... } & Help & Close & \\
\hline
\end{tabular}

Figure 20 - Data Statistics for Low Load Healthy State (Magnitude) 


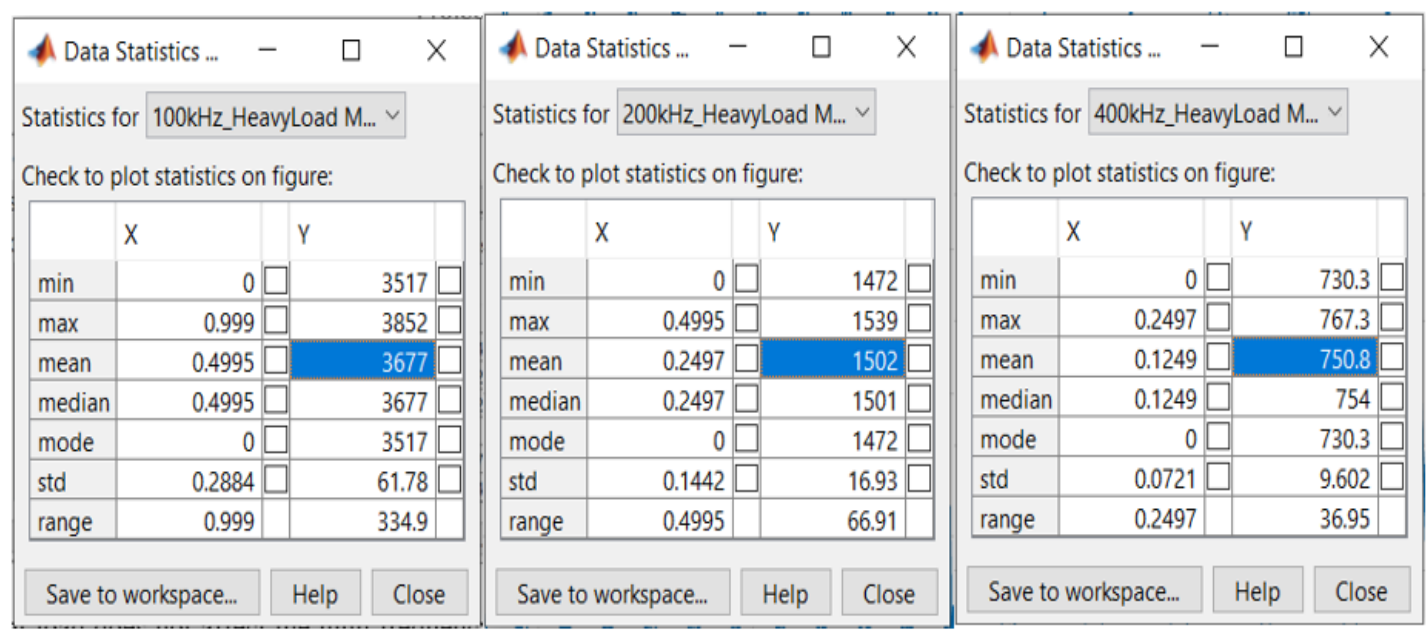

Figure 21 - Data Statistics for Heavy Load Healthy State (Magnitude)

As such, we can conclude that load does not affect the high frequency impedance of the induction motor. This part is essential as it ensure that any changes in the impedance is a result of a potential fault and not due to the change in load.

\section{Stator Winding Insulation Faults Detection}

After obtaining the healthy state impedance of the induction motor, simulation for the emulated interturn short circuit and coil-to-coil short circuit faults under the same conditions are conducted. The interturn short circuit fault is when the two turns of the same phase are shorted together as shown in Figure 22. Coil to Coil Short Circuit fault occurs when two coils of the same phase are shorted together as shown in Figure 23.

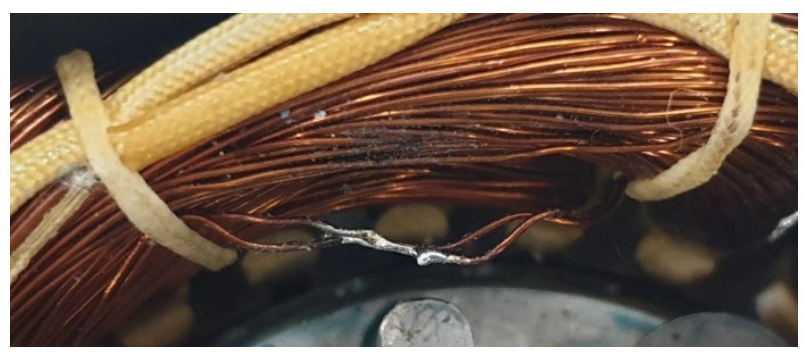

Figure 22 - Emulated Inter-Turn SC Fault

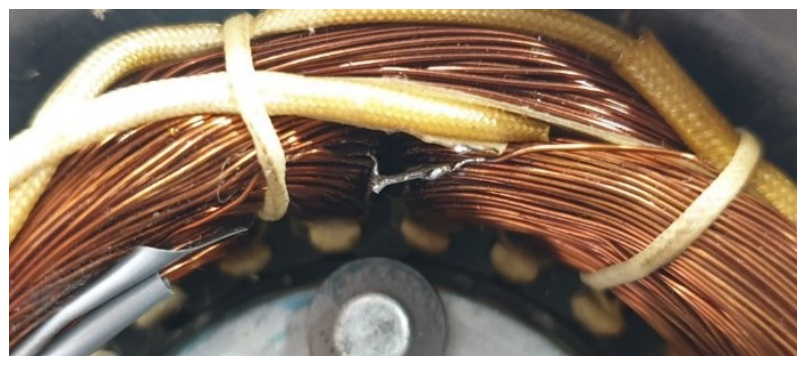

Figure 23 - Emulated Coil to Coil SC Fault

Under the following conditions, the impedance of the induction motor in its emulated fault conditions are extracted.

When light load is attached to the induction motor, 
Figures 25 and 26 show the magnitude of the measured impedance of the induction motor under the two emulated faults, respectively.

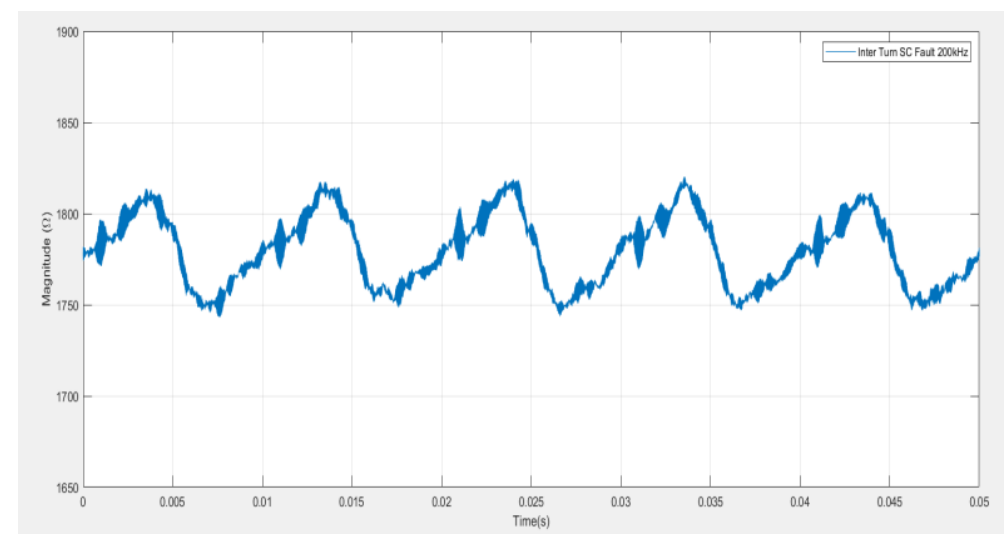

Figure 24 - Light Load Inter-Turn SC Magnitude, Fsig200kHz, Fs2MHz

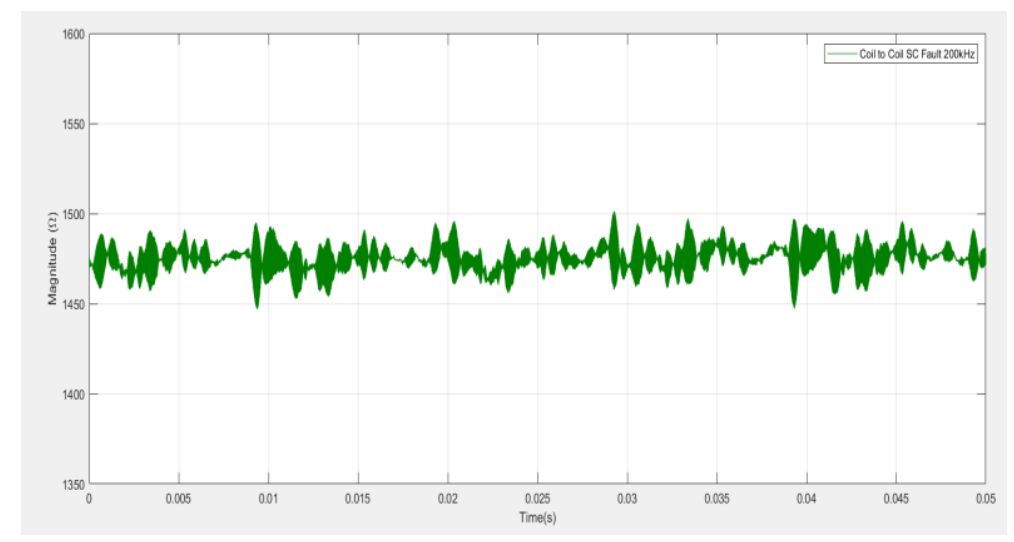

Figure 25 - Light Load Coil to Coil SC Magnitude, Fsig200kHz, Fs $2 \mathrm{MHz}$

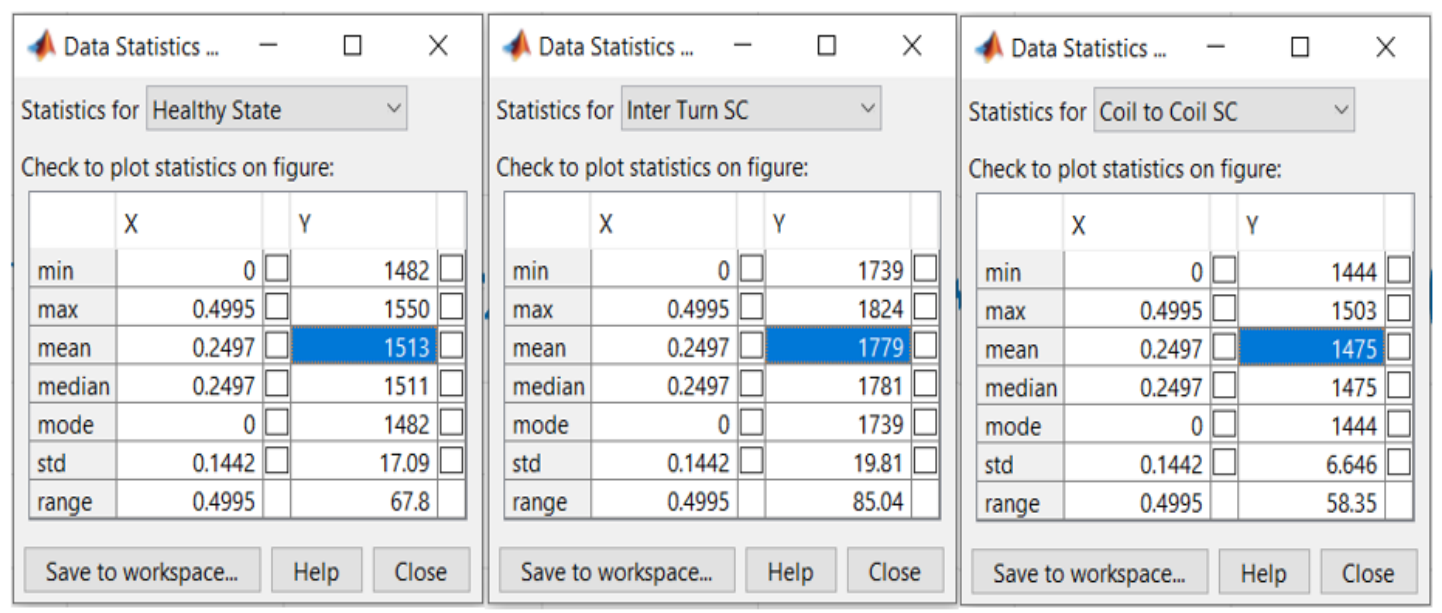

Figure 26 - Data Statistics for the Different Conditions at frequency $200 \mathrm{kHz}$

From Figures 24 and 25, they represent the magnitude at healthy state, inter-turn SC condition and coil to coil SC condition respectively, the online impedance deviates when a fault occurs. This can also be observed from the data statistics of the individual conditions as shown in Figure 26. At the same time, when the inter turn SC fault was identified, the fault has not escalated into a major breakdown, which 
distinctly prove the importance of the suggested technique in the maintenance process of an induction motor. Subsequently, the same procedure is repeated for the induction motor at $100 \mathrm{kHz}$ and $400 \mathrm{kHz}$ to validate the capability of the suggested method to function at different frequencies. Figures 27 and 28 below show the results obtained.

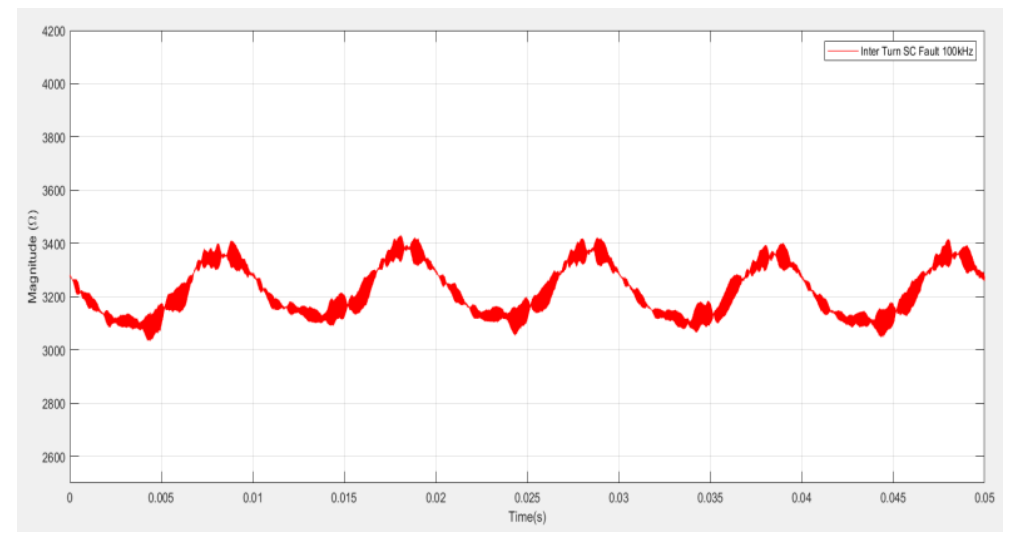

Figure 27 - Light Load Inter Turn SC Magnitude, Fsig100kHz, Fs $1 \mathrm{MHz}$

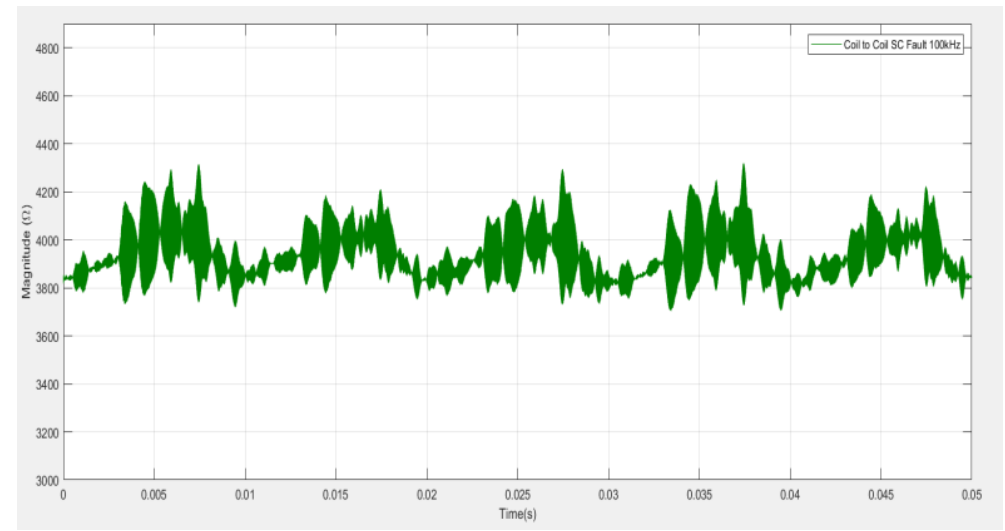

Figure 28 - Light Load Coil to Coil SC Magnitude, Fsig100kHz, Fs $1 \mathrm{MHz}$

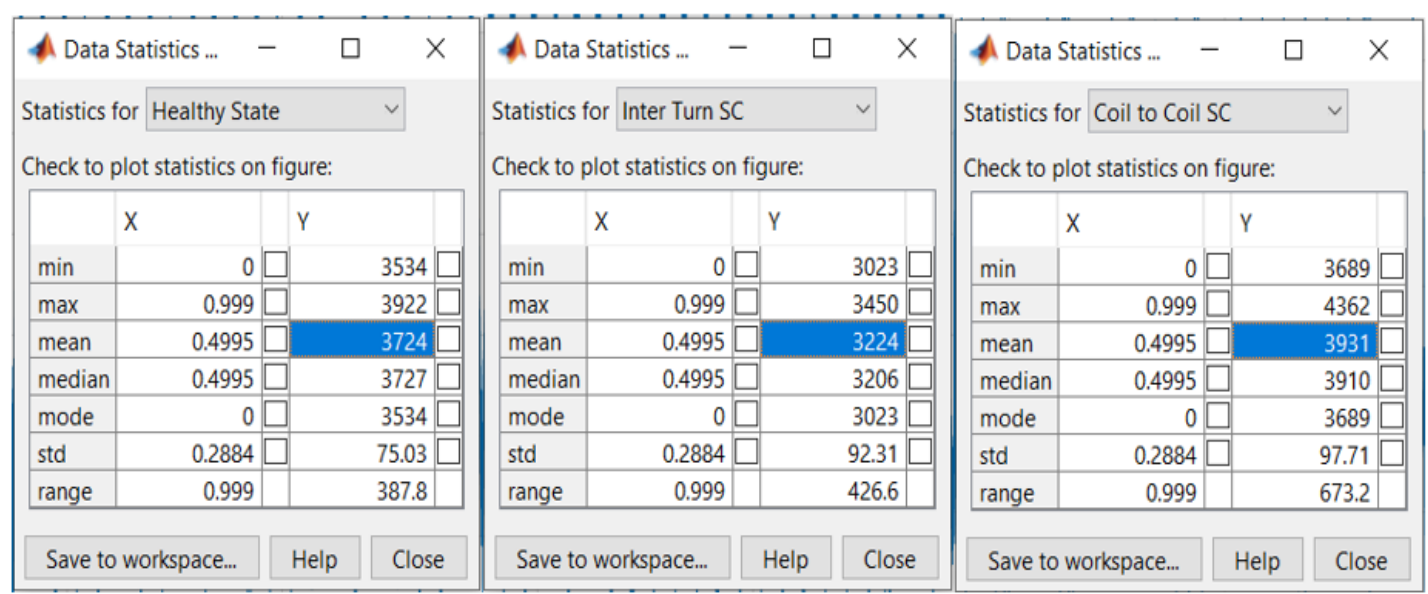

Figure 29 - Data Statistics for the Different Conditions at frequency $100 \mathrm{kHz}$

At $100 \mathrm{kHz}$ frequency level, the induction motor healthy state impedance is $3724 \Omega$. When the motor encounter inter turn SC fault, the impedance falls to $3224 \Omega$. At the same time, when the motor encounters a coil to coil fault, the impedance increases to $3931 \Omega$ as shown in the data statistics table in Figure 29. The waveform of the impedance magnitude also shows signs of the deviation during fault 
condition as seen in Figure 27 and Figure 28. The following figures below shows the same results at frequency level of $400 \mathrm{kHz}$. At $400 \mathrm{kHz}$ frequency level, the induction motor healthy state impedance is $747.9 \Omega$. When the motor encounter inter turn SC fault, the impedance deviates to $759.8 \Omega$. At the same time, when the motor encounters a coil to coil fault, the impedance increases to $854.2 \Omega$ as shown in the data statistics table in Figure 32. The waveform of the impedance magnitude also shows signs of the deviation during fault condition as seen in Figure 30 and Figure 31.

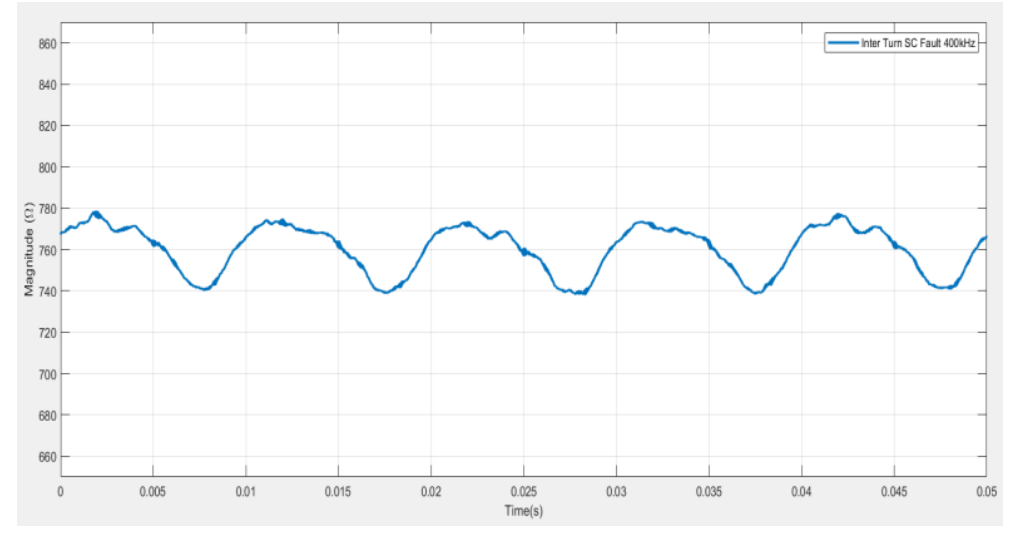

Figure 30 - Light Load Inter Turn SC Magnitude, Fsig400kHz, Fs4MHz

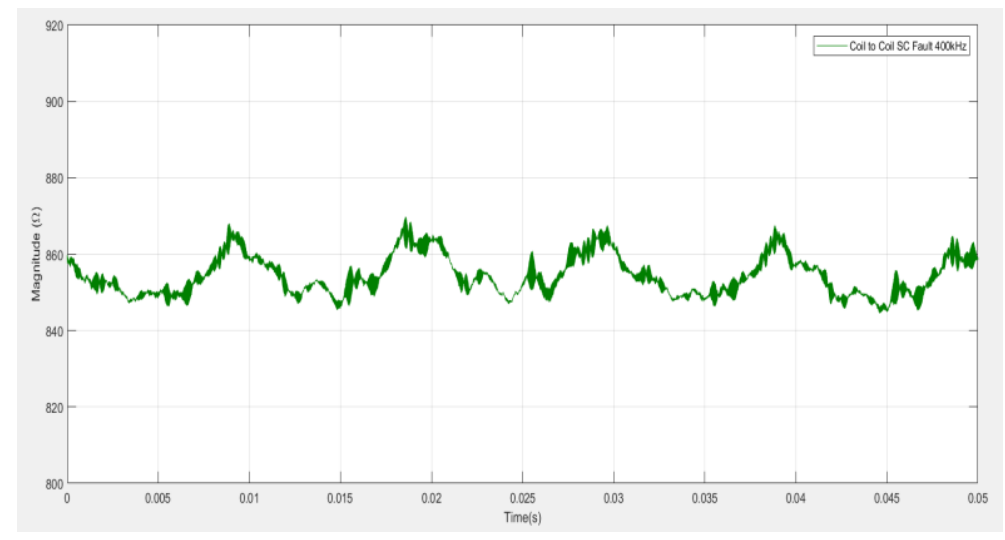

Figure 31 - Light Load Coil to Coil SC Magnitude, 2Fsig400kHz, Fs $4 M H z$

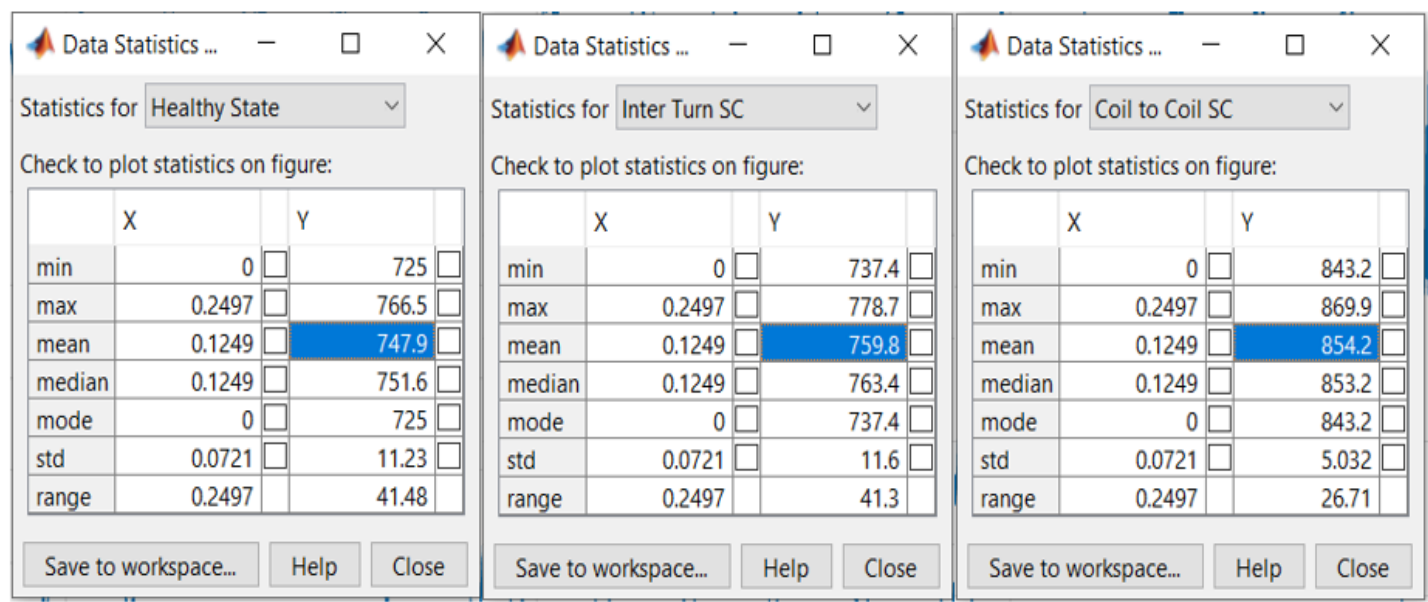

Figure 32 - Data Statistics for the Different Conditions at frequency $400 \mathrm{kHz}$

As seen from the figures, the proposed method can detect faults in the stator windings of the induction motor despite the frequency level. 


\section{Conclusion}

The non-intrusive impedance extraction technique as proposed in this paper has shown good potential in detecting stator windings fault within the induction motor. It does not require any direct electrical connection with the power supply connecting to the induction motor. Hence it removes any safety hazards when conducting condition monitoring. At the same time, it is more cost and time efficient as its installation and removal is less complex as compared to other methods.

\section{References}

[1] B. Asad, T. Vaimann, A. Belahcen, A. Kallaste, A. Rassõlkin, and M. N. Iqbal, "Broken rotor bar fault detection of the grid and inverter-fed induction motor by effective attenuation of the fundamental component," IET Electr. Power Appl., vol. 13, no. 12, pp. 2005-2014, 2019, doi: 10.1049/iet-epa.2019.0350.

[2] G. K. Singh and S. A. S. A. Kazzaz, "Induction machine drive condition monitoring and diagnostic research-a survey," Electr. Power Syst. Res., vol. 64, no. 2, pp. 145-158, 2003, doi: 10.1016/S0378-7796(02)00172-4.

[3] A. H. Bonnett and G. C. Soukup, "Cause and analysis of stator and rotor failures in three-phase squirrel-cage induction motors," IEEE Trans. Ind. Appl., vol. 28, no. 4, pp. 921-937, Jul./Aug. 1992, doi: 10.1109/28.148460.

[4] R. A. Southwick and W. C. Dolle, "Line impedance measuring instrumentation utilizing current probe coupling," IEEE Trans. Electromagn. Compat., vol. EMC-13, no. 4, pp. 31-36, Nov. 1971, doi: 10.1109/TEMC.1971.303150.

[5] Z. Zhao et al., "Online insulation fault detection of stator winding of induction motor based on a non-intrusive impedance extraction technique," in Proc. IEEE Int. Conf. Intelligent Rail Transportation (ICIRT), Singapore, 2018, pp. 1-5, doi: 10.1109/ICIRT.2018.8641627.

[6] A. S. Narayanan et al., "Study on the parameters affecting the impedance extraction accuracy by inductive coupling method," in Proc. IEEE Int. Conf. Intelligent Rail Transportation (ICIRT), Singapore, 2018, pp. 1-5, doi: 10.1109/ICIRT.2018.8641624.

[7] Z. Zhao, K. Y. See, E. K. Chua, A. S. Narayanan, W. Chen, and A. Weerasinghe, "Time-variant in-circuit impedance monitoring based on the inductive coupling method," IEEE Trans. Instrum. Meas., vol. 68, no. 1, pp. 169-176, Jan. 2019, doi: 10.1109/TIM.2018.2838198.

[8] Z. Zhao, K.-Y. See, E.-K. Chua, A. S. Narayanan, A. Weerasinghe, and W. Chen, "Extraction of voltage-dependent capacitances of $\mathrm{SiC}$ device through inductive coupling method," in Joint Proc. IEEE Int. Symp. Electromagn. Compat. and Proc. Asia-Pacific Int. Symp. Electromagn. Compat. (Joint EMC \& APEMC), Singapore, 2018, pp. 1301-1304, doi: 10.1109/ISEMC.2018.8393999.

[9] D. M. Pozar, Microwave engineering. Hoboken, NJ, USA: Wiley, 2012. 